\title{
Development of an Experimental Setup for Remote Testing of Pneumatic Control
}

\author{
https://doi.org/10.3991/ijoe.v14i01.7784 \\ Vule Reljić( $\left.{ }^{(}\right)$, Brajan Bajči, Ivana Milenković, \\ Jovan Šulc, Dragan Šešlija, Slobodan Dudić \\ University of Novi Sad, Novi Sad, Serbia \\ vuketa90@uns.ac.rs
}

\begin{abstract}
This paper presents an experimental setup called pneumatic circular manipulator. The manipulator represents a modular setup that can be adapted for the new testing by simple transformations. It is intended to be used for testing various types of pneumatic control and energy efficiency of pneumatic control systems. The manipulator is primarily designed for students and their lectures. Since it has the possibility for remote control over the Internet, due to its modularity, it can be very interesting for researchers and employees in industry. The existing version of the manipulator allows visual monitoring of the working cycle and familiarization with the basics of pneumatic control and motion control for users. By future upgrade, the manipulator will become a setup that will provide feedback on the consumption of compressed air, analysis of the type of control, cost-effectiveness analysis, etc.
\end{abstract}

Keywords—remote control, pneumatic control, manipulator, CEyeClon platform

\section{Introduction}

Reducing costs and reducing energy consumption have long been a major focus for industrial experts [1-3]. The energy required for manufacturing operations is considered as an input of the process, which is partially transformed into useful work, embodied into the form and composition of the products and wastes while the rest is transformed into waste/lost heat. Energy savings are expected to be achievable from increasing both the energy efficiency of production and the logistic processes, as well as in innovative energy monitoring and management approaches, leading industries to a way of producing "more with less" [4].

Testing the various methods for reducing costs and energy consumption can sure reduce the mismatch between perceived and real barriers. Considering that greater knowledge leads to the decision of an industrial manager on how they are clearly confronted with effective opportunities and threats [5]. For a realistic estimate of cost and energy savings, at least one experimental setting is extremely valuable. It is necessary to provide different types of testing and analysis in most situations that may arise in practice. In the case of pneumatic control, it is necessary to identify the most common situa- 
tions which is applied for the implementation of standard industrial tasks [1]. In addition, it is necessary to identify the groups of actuators that are most often used to observe these tasks. These are pneumatic cylinders and pneumatic grippers.

In this paper is presented an experimental setup called pneumatic circular manipulator which will be used as a test bed for testing various types of pneumatic control and energy efficiency of pneumatic systems. Also, it is important to note that the manipulator has the possibility of remote control.

\section{Development of the existing version of pneumatic circular manipulator}

Pneumatic circular manipulator performs simple mechanical operations, typical for industrial handling of workpieces, such as excluding workpieces from the storage unit, transferring to a new workplace (e.g. for machining) and re-storing to the intended location. It is conceived as a modular setup. By simple transformations, it can be adapted to a different mode of pneumatic control [6]. The manipulator consists of four pneumatic cylinders and one pneumatic gripper. One of the cylinders is multi-position cylinder which is made of two identical double acting pneumatic cylinders. The basic version of manipulator is shown in Fig. 1. Actuators are marked with A, B, C and D that represents pneumatic cylinders and $\mathrm{E}$ for a pneumatic gripper.

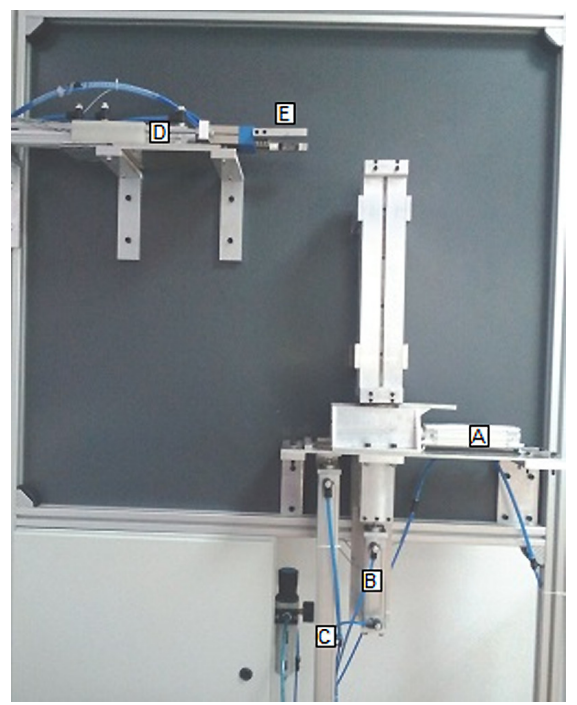

Fig. 1. The basic version of pneumatic circular manipulator

By using standard order control, the manipulator performs one working cycle as follows: cylinder A pushes one workpiece forward from vertical storage unit to the cylinder $\mathrm{C}$ that accepts it and raises to a higher level. During this time, cylinder B holds remaining workpieces in the storage unit and in the next step cylinder A returns 
to its initial position. By moving the multi-position cylinder D into the second of the three possible positions, the gripper is brought into the position for accepting the workpiece. By the next moving of the multi-position cylinder (far right), the gripper is brought directly above the storage unit. In the next step, the gripper opens and releases the workpiece. Simultaneously, all remaining actuators return to their initial positions. In this way, by repeating the working cycle, the workpieces circulate through the system. From there come the name of the manipulator.

Pneumatic circular manipulator includes various operations of pneumatic actuators that occurs in industrial processes: horizontal exclusion of workpieces from the storage unit, horizontal acceptance and release of workpieces, vertical lifting or lowering of workpieces etc.

Below is one of many possible transformations of the manipulator. The manipulator is flexible to simulate different situations that occurs in the industrial process, such as compression, bending and straining. In order to the user find out which load is the most favorable and the most economical in a given situation, an appropriate tests should be carried out. So, for example, by using pneumatic circular manipulator, it is possible to analyze what is happening with consumption of compressed air when the piston rod of cylinder is under load (cylinder $C$ that raises the workpiece vertically upwards). The ratio of the forces is shown in Fig. 2. The load is marked with $\mathrm{Mg}$.

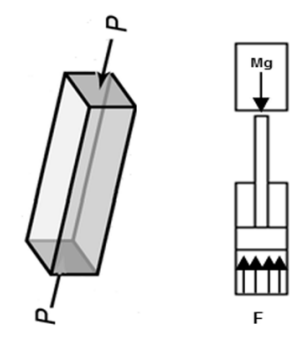

Fig. 2. Type of load (left) and situation in system (right) - compression

\subsection{Possibilities for transformations of mechanical structure of the manipulator}

In order to be able to analyze consumption of compressed air for other types of load, a slight mechanical corrections will be made. In the case when the double acting pneumatic cylinder $\mathrm{C}$ is replaced with a roadless pneumatic cylinder, it is possible to analyze how the consumption of compressed air changes in the case of bending. On its outer side, this cylinder has a load carrier as is shown in Fig. 3 (left).

In the third case, when the straining load is analyzed, the same cylinder can be used as in the first case. The difference is that the cylinder is mounted upside down and has attached vacuum cup at the top of the piston rod. In addition, the active force is also lower as is shown in Fig. 3 (right). 

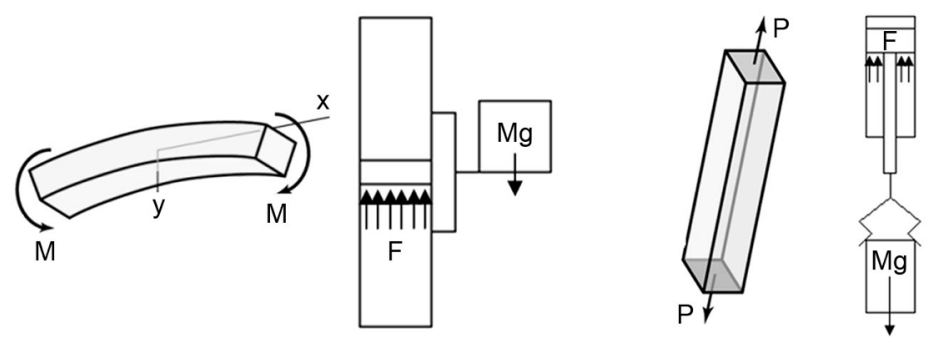

Fig. 3. Type of load - bending (left) and straining (right)

With simple mechanical transformations, the manipulator can be adapted to simulate a variety of different ways of handling workipeces that occur in industrial processes, in which there are different types of loads. In addition to load change and energy consumption analysis in those cases, by using this manipulator it is possible to change type of control. For example, instead the traditional control of pneumatic actuators, it is possible to apply proportional valves and proportional control etc. Also, in the reverse order of movement (change of control steps), it is possible to simulate the situation when workpieces are lifted through a vertical storage unit, which also happens in handling of workipeces. All this can be done on a unique test bed and that is its main advantage.

\section{Remote control of pneumatic circular manipulator}

The possibility of remote control is what the pneumatic circular manipulator distinguishes from other similar experiment setups. This experimental setup is developed at Faculty of Technical Sciences in Novi Sad (FTS NS), Serbia and as such, it is primarily intended for students of that faculty. It is currently used as teaching tool in courses in Components of Technological Systems, Automation of Work Processes, Implementation of Automated Systems, Motion Control, etc. Within these subjects students learn about the basics of pneumatic systems, the basics of pneumatic actuators and motion control (the manipulator is a representative model for the order control), how to properly choose pneumatic actuators and other pneumatic components, etc. Due to the possibility to remotely control the manipulator and work from their home, students have the opportunity to create their own schedule on their own wishes [7-9]. Besides the students of FTS NS, the manipulator is used by the students and researchers from other faculties dealing with similar fields. In the future, the manipulator will be used as the main teaching tool in the course Energy Efficiency of Compressed Air Systems. In addition, the users of the manipulator will be employees in the industry who need a representative model for some realistic testing. The implementation of laboratory equipment called Air Box by the manufacturer Festo, which enables the measurement of air flow and consumption of compressed air in the system and the collection of these data, will allow analysis of the energy efficiency of various pneumatic systems. This is the basic purpose of a pneumatic circular manipulator. 
The remote control of pneumatic circular manipulator is performed using CEyeClon platform [10]. The CEyeClon platform is developed for industrial purposes, and then upgraded for distance learning. Compared to other standard remote control possibilities, the platform shows some advantages. For example, what was the most important for us, security check is in high level, unlike Team Viewer. Further, there is no need for disconnection of Windows Firewall or Antivirus, unlike standard LabView applications. The adding of new experiment on CEyeClon is more simply and easy, unlike remote control using standard web application for any controller which has the ability to enter the application. Of course, the platform shows some disadvantages. Distance learning is still easier with Moodle for the possibility to generate a large number of different tests. For the functioning of the platform, it is also necessary to provide a Raspberry Pi that representing the server, unlike standard web application.

To successfully connect with an experimental setup, for the users it is necessary to have the CEyeClon Viewer software and a stable Internet connection. With an entering correct user name and password which are obtained from the administrator team, the users connect to the remote desktop which is placed in faculty laboratory. By running the user application "Circular_Manipulator.exe" which is installed on the desktop, the experiment is started. The remote desktop and the main control device (programmable logic controller) are connected via RS232. The ways of communication in the system are shown in Fig. 4.

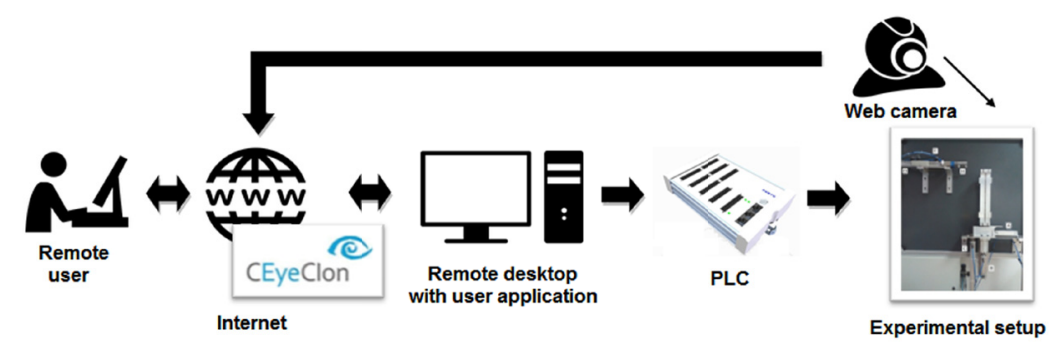

Fig. 4. Ways of communication in the remote system

The currently developed user application includes control of working cycle of the basic version of the manipulator. As such, it is mainly intended for students familiar with basic concepts in the field of pneumatic control, motion control, etc. The application is developed in object-oriented programming language LabView. The application involves selecting the operating mode of the manipulator - single cycle, single cycle with delay and automated mode ( 6 cycles). These different control types can be selected by entering "A", "B" or "C" in the "Control type selection" field, respectively. Before starting an experiment, it is necessary to set serial communication parameters for successful transfer of commands to the PLC that controls the working cycle of the manipulator. The manipulator starts working by pressing the black arrow button in the title bar. The user application is shown in Fig. 5.

The manipulator can be started only in the case of the correct mode selection. In this case, in the "Checking input parameters" field, the following will be printed: "Look at the camera!", because it is possible to monitor the experiment through a webcam. The 
camera works from the VLC player. In the case of incorrect entry, in the field "Checking input parameters" the following will be written: "Error! Please, enter correct parameters!"

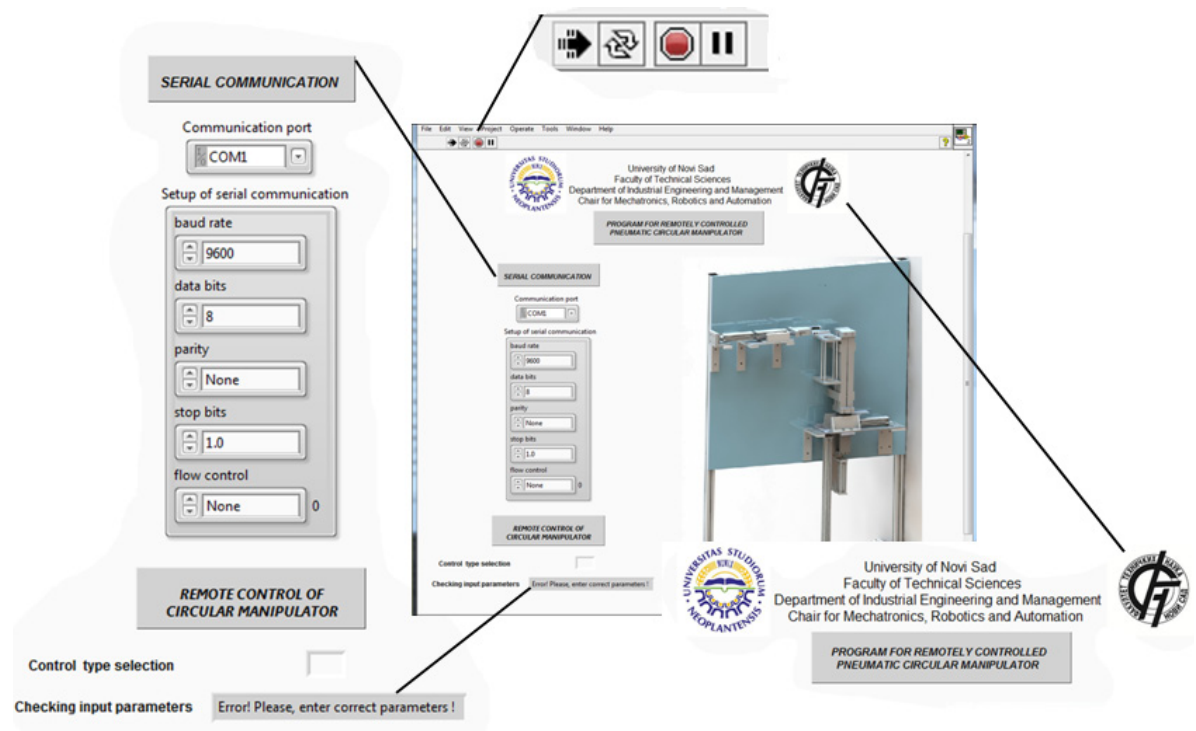

Fig. 5. User application

\section{Conclusions}

One of the main tasks of today's industrial systems is to increase efficiency by reducing energy consumption. In order to achieve any shift in this direction, it is necessary to collect all important information and to analyze all possible situations. Only with the wider perspective the new solutions can be proposed. Of course, the ideal case is to test new method/approach on a representative model before applying it in a real industrial system.

The pneumatic circular manipulator is one of these models and was developed at FTS NS. This manipulator will be used to test various types of pneumatic control and energy efficiency of pneumatic control systems. It is intended for students, but also for all other engineers and researchers who want to learn more about this field. Therefore, the remote control of manipulator is enabled over the Internet.

For now, the basic version of the manipulator has been developed and used in teaching. The future works relate to the implementation of new modules on the manipulator, the improvement of the existing mechanical construction and the development of new user applications. These applications will contain significantly more options related to different types of control, as well as information about the consumption of the compressed air. In addition, further researches would focus on the development of complex robot cell shown in Fig. 6 (CAD model). It consists of a standard industrial robot (Fig. 6, left), a pneumatic circular manipulator (Fig. 6, middle) 
and biaxial pneumatic (Fig. 6, right) for a contact tasks. It is planned to install some measuring devices and enable measurement of the electrical energy consumption and compressed air consumption, the pressure of compressed air and the time required for certain tasks. Realization of this cell will enable new tests in the field of energy efficiency and optimization of various parameters.

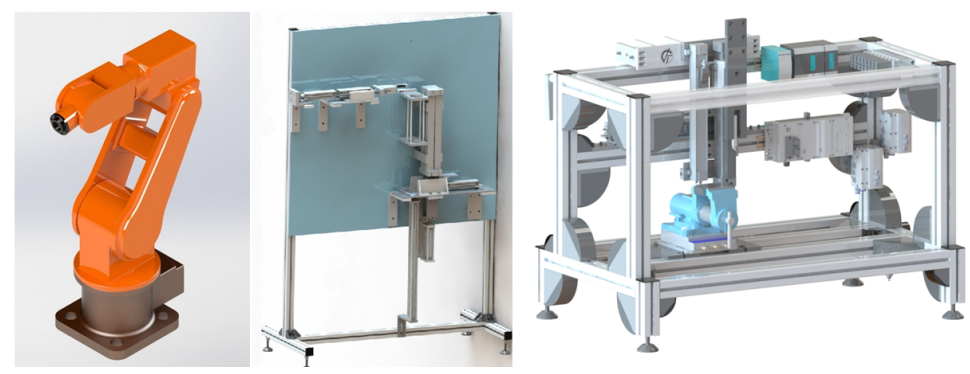

Fig. 6. Parts of complex robot cell

\section{Acknowledgment}

This paper presents the outcome of the NeReLa project "Building Network of Remote Labs for strengthening university-secondary vocational schools collaboration", No. 543667-TEMPUS-1-2013-1-RS-TEMPUS-JPHES, supported by The Education, Audiovisual and Culture Executive Agency (EACEA).

\section{$6 \quad$ References}

[1] I. Ignjatović et all (2013). "Optimisation of Compressed Air and Electricity Consumption in Complex Robotic Cell”, Robotics and Integrated Manufacturing, Vol 29, No 4, pp. 7076 https://doi.org/10.1016/j.rcim.2012.11.001

[2] E. A. Abdelaziz, R. Saidur, S. Mekhilef (2011), "A Review on Energy Saving Strategies in Industrial Sector", Renewable and Suistanale Energy Reviews, Vol 15, No 1, pp. 150$168 \mathrm{https} / / /$ doi.org/10.1016/j.rser.2010.09.003

[3] D. Ššlija, I. Ignjatović, S. Dudić (2012). "Increasing the Energy Efficiency in Compressed Air Systems" In: Energy Efficiency the Innovative Ways for Smart Energy, the Future Towards Modern Utilities, pp. 151-174

[4] F. Apostolos et all (2013). "Energy Efficiency of Manufacturing Processes: A Critical Review", Procedia CIRP, Vol 7, pp. 628 - 633 https://doi.org/10.1016/j.procir.2013.06.044

[5] A. Trianni, E. Cagno, A. De Donatis (2014). "A framework to characterize energy efficiency measures", Applied Energy, Vol 118, pp. 207-220 https://doi.org/10.1016/j.ap energy.2013.12.042

[6] V. Reljić et all (2016). "Modular Construction of Circular Manipulator as a Test Bed for Testing Pneumatic Control”, Proceedings of KOD 2016, $9^{\text {th }}$ International Symposium and Industrial Desing in Mechanical Engineering, Balatonfured, Hungary

[7] S. Suwannakhun, T. Tanitteerapan, (2017). "Design and Development of Distance Laboratory Package for Teaching Basic Electronics via Cloud Computing", International Journal of Online Engineering (iJOE), Vol 13, No 8, pp. 60-78, https://doi.org/10.3991/ ijoe.v13i08.6985 
[8] H. Guerra et all (2016). "Remote Experiments as an Asset for Learning Programming in Python", International Journal of Online Engineering (iJOE), Vol 12, No 4, pp. 71-73, https://doi.org/10.3991/ijoe.v12i04.5278

[9] S. D. Gadzhanov, A. Nafalski, Z. Nedic, (2014). "Remote Laboratory for Advanced Motion Control Experiments", International Journal of Online Engineering (iJOE), Vol 10, pp. 43-51, https://doi.org/10.3991/ijoe.v10i5.3835

[10] T. Zurcher, A. Rojko, D. Hercog (2015). "Education in Industrial Automation Control by Using Remote Workplaces", Proceedings of IEEE Exp. at '15, $3^{\text {rd }}$ Experiment@ International Conference Online Experimentation, Azores, Portugal

\section{Authors}

Vule RELJIĆ is a MSc in Mechatronics from the University of Novi Sad, Serbia. $\mathrm{He}$ is a $\mathrm{PhD}$ student and is enrolled at the Department of Industrial Engineering and Management at the Faculty of Technical Sciences, University of Novi Sad, Serbia as a teaching assistant. His research interest includes pneumatic systems and control, remote control and web programming.

Brajan BAJČI is a MSc in Mechatronics from the University of Novi Sad, Serbia. $\mathrm{He}$ is a PhD student and is enrolled at the Department of Industrial Engineering and Management at the Faculty of Technical Sciences, University of Novi Sad, Serbia as a teaching assistant. His research interest includes pneumatic systems and control, remote control, industrial automation and web programming.

Ivana MILENKOVIĆ received PhD in Industrial Engineering from the University of Novi Sad, Serbia, in 2014. She is currently assistant professor at the Department of Industrial Engineering and Management at the Faculty of Technical Sciences, University of Novi Sad, Serbia. Her research interests include remote experiments, compressed air systems, filtration of compressed air, sustainable production and energy efficiency.

Jovan ŚULC received his PhD in Mechatronics from the University of Novi Sad, Serbia, in 2016. He is currently assistant professor at the Department of Industrial Engineering and Management at the Faculty of Technical Sciences, University of Novi Sad, Serbia. His research interest is related to remote control, pneumatics and energy efficiency.

Dragan ŠEŠLIJA received his PhD in Robotics from the University of Novi Sad, Serbia, in 1997. He is currently full professor at the Department of Industrial Engineering and Management and Vice Dean for Science and International Cooperation at the Faculty of Technical Sciences, University of Novi Sad, Serbia. He is an expert in pneumatics, energy efficiency and remote experiments.

Slobodan DUDIĆ received $\mathrm{PhD}$ in Industrial Engineering from the University of Novi Sad, Serbia, in 2012. He is currently associate professor at the Department of Industrial Engineering and Management at the Faculty of Technical Sciences, University of Novi Sad, Serbia. His research interests include remote experiments, compressed air systems, filtration of compressed air, sustainable production and energy efficiency.

Article submitted 02 October 2017. Published as resubmitted by the authors 13 December 2017. 